\title{
Project Morpheus Main Engine Development and Preliminary Flight Testing
}

\author{
Robert L. Morehead ${ }^{1}$ \\ NASA/Johnson Space Center, Houston, TX, 77058
}

\begin{abstract}
A LOX/Methane rocket engine was developed for a prototype terrestrial lander and then used to fly the lander at Johnson Space Center. The development path of this engine is outlined, including unique items such as variable acoustic damping and variable film cooling.
\end{abstract}

\section{Nomenclature}

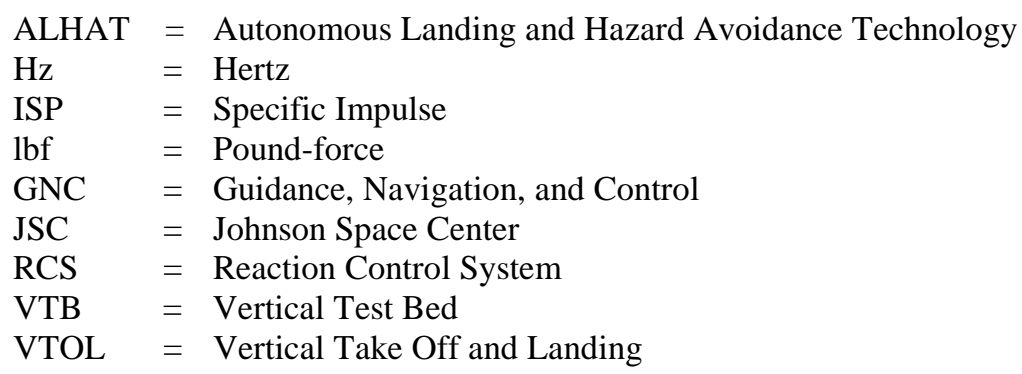

\section{Introduction}

$\mathrm{T}$ The NASA/Johnson Space Center Vertical Test Bed (VTB, a.k.a. Morpheus) is an integrated testing platform capable of short VTOL flights using liquid oxygen and liquid methane propellants for both the main engine and RCS systems ${ }^{2}$. This paper outlines the development of the main engine for the VTB.

Morpheus main engine requirements: 4,200 lbf thrust, $215 \mathrm{sec}$ ISP, a 4:1 throttle range, and a minimum run time of 210 seconds. The VTB is designed to operate with or without active propellant pressurization, so the engines must also be able to operate under stable pressure or blowdown operation. Additionally, the engine must be able to respond to changes in desired thrust very quickly and be insensitive to rapid engine rotation due to gimballing.

\section{Morpheus - a "Vertical Test Bed"}

The Morpheus vehicle is an autonomous flying robot created to test lander technologies in a flight environment. Near-term experiments include the ALHAT system, piezoelectric valve flight testing, GNC sensor testing, and RCS flight testing. Morpheus operates at JSC on the purpose built Vertical Flight Complex for hover and short translation flights up to one minute in duration. Flights up to 3 minutes in duration will occur at the White Sands Test Facility.

Morpheus weighs $~ 1,700$ lbs dry and can carry up to 2,100 lbs of liquid oxygen and liquid methane in four spherical aluminum tanks. The propellant tanks are pressurized with helium and operate in a blowdown configuration for short duration flights. Onboard high pressure helium tanks are planned for later phases of Morpheus development and will enable long duration flights with larger propellant loads. The main engine is mounted in a two-axis gimbal anchored to the bottom deck of the vehicle, with the nozzle extending slightly below deck level.

[Figure 1: CAD or picture of Morpheus vehicle/propulsion system]

\footnotetext{
${ }^{1}$ Propulsion Engineer, Propulsion and Power, NASA/JSC/EP4

${ }^{2}$ To be installed in late 2011
} 
Final assembly of the Morpheus vehicle began in January of 2011. The first engine hotfire took place on 4/14/2011, with the vehicle tethered to both a crane and to the ground. The first hover flight test occurred on 4/27/2011, with the vehicle tethered to a 100-ton crane for safety. Several other tethered hover flights have occurred since then, and the first free flight of Morpheus is planned for the summer of 2011.

\section{Morpheus Main Engine}

Engine development for Morpheus was driven by two tenets - low cost and rapid development. This translated into creating inexpensive ways to solve classic rocket engine problems and low numbers of test firings with many objectives per test.

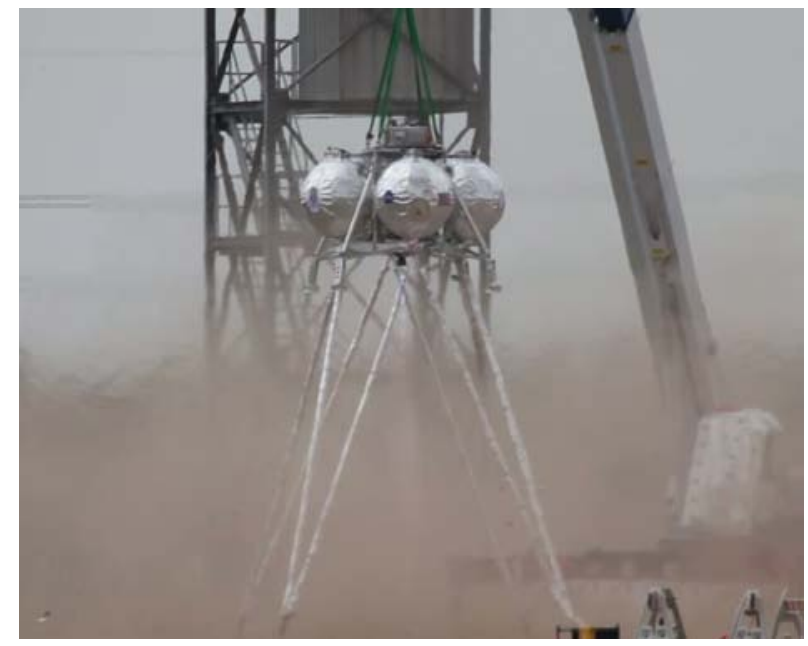

Figure 2: Morpheus Hot Fire Test (strap-down configuration)

This engine series uses an impinging element injector and a film cooled combustion chamber. Neither selection is state of the art but these established technologies facilitated rapid, inexpensive development of an engine that can run continuously.

The price for the engine's simplicity was performance. In some cases, over $30 \%$ of the engine's fuel was used to film cool the chamber walls and exited the engine unburned. Methane is not as efficient at film cooling as alcohol, kerosene, or other liquid fuels but its low mass makes up for some of that poor performance. On the Morpheus engines, the methane film coolant is injected as a liquid but is vaporized within the first 2-3 inches downstream of the injector. The majority of the combustion chamber and nozzle, therefore, are cooled with locally low temperature methane gas.

\section{A. HD1}

The initial engine developed for Morpheus, dubbed "HD1" was 2,700 lbf thrust, intended for short duration hover flights. This engine utilized 132 like-impinging doublets, arranged in pairs or triplets such that the resulting fans were forced to overlap in their ligament zones with the combined mass flow pointing through the nozzle throat. The orifices were sized with the intent of avoiding combustion instabilities at high thrust and feed system chugging at low thrust, using empirical instability data from previous impinging element injectors. (references?) Acoustic damping devices were not used on this engine.

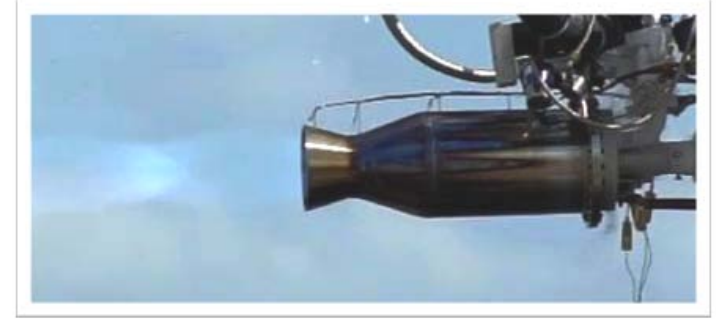

Figure 3: Morpheus HD1 Engine at 70\% Power Level

The injector housing was a sandwich-stack of four plates, welded together and creating two methane cavities and one oxygen cavity. Oxygen was delivered to groups of 1-3 orifices on the injector face via hollow columns milled into the backside of the injector face and welded into the methane cavity cap plate - passing through the main methane manifold. The liquid oxygen manifold was a milled cavity welded on top of the methane cap plate, and all three parts were then welded into the injector housing which also then formed the outer film cooling manifold. Lastly, engine thrust is transferred via a post in the center of the injector, which also acts as the methane inlet to the injector. Inspired by Armadillo Aerospace injector manufacturing, this stacked-plate method is highly reliant on critical joint welding but facilitated rapid, inexpensive production.

The combustion chamber and nozzle were cooled by methane film cooling, injected in a single ring of orifices along the perimeter of the injector, through an independent variable flowrate methane manifold. This variability was 
intended to allow optimization the engine's specific impulse by maximizing the allowable chamber wall temperature through minimizing the quantity of methane used for film cooling. All tests of this engine, however, were performed with the film cooling valve at $100 \%$ open, resulting in $\sim 32 \%$ of the engine methane flow being used for film cooling.

This engine configuration was tested twice in September of 2010 on the Armadillo Aerospace test stand in Caddo Mills, Texas. The initial 10 second test firing at 70\% power level produced an ISP of 190 seconds, with the engine operating at the desired levels for thrust and internal pressure losses (Figure 1). The chamber wall temperature was higher than predicted although the chamber and injector bluing were normal for this type of engine. A slight tone was heard during this test, later identified as 1,350 and $2,700 \mathrm{~Hz}$ instabilities via microphones at the pad. The second engine test at $100 \%$ power level was cut-off at 3.5 seconds due to an obvious change in the exhaust plume. Post test inspections revealed extensive damage to the injector face and a rupture in the chamber wall - caused by a $4,400 \mathrm{~Hz}$ spinning $1^{\text {st }}$ tangential instability.

Notional data from this and other liquid methane engines suggests that liquid oxygen/liquid methane impinging element engines tend to be more prone to instability than those engines using less volatile fuels (when compared using the injector $\mathrm{d} / \mathrm{V}$ method). The high vapor pressure of liquid methane relative to other liquid fuels may contribute to this inclination - more research is warranted.

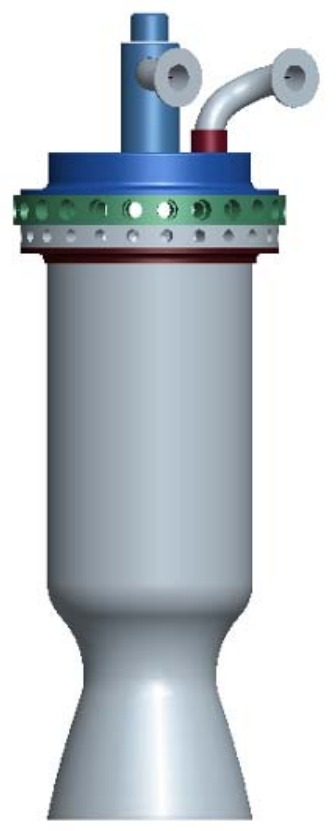

Figure 4: HD3 Engine

\section{B. HD2}

Following the test stand failure of HD1, two attempts were made to rebuild and improve the low-thrust engine. The core effort focused on replacing the injector face by brazing a new faceplate onto the HD1 injector housing and oxygen columns, extending from the internal (undamaged) oxygen manifold. Interplate motion during the furnace brazing proved too much for the braze bonds, though, and minor oxygen to methane manifold leakage was detected following each attempt. Hence, the HD2 engine was abandoned and we moved on to HD3: a full-thrust engine for Morpheus.

\section{HD3}

Based on the lessons learned from the previous engines, HD3 was designed, built, and tested in nine weeks - culminating in the first test firing series on January 25, 2011. This engine was slightly modified twice to improve film cooling, with intermediate test firings, and was then hot fired on the Morpheus vehicle on April 14, 2011. The engine has been used in this configuration (HD3.2) on Morpheus for two days of hot fire testing and five vehicle flights under tether.

The HD3 engine is rated at 4,200 lbf and utilizes a similar injector: 132 like impinging doublets arranged in overlapping pairs and triplets, variable flow film cooling, and a sandwich-stack injector construction. Upgrades to this engine include a variable position acoustic cavity ring, a nozzle made of Haynes 625, and an upgraded injector pattern including targeted mixture ratio zoning (Figure 4).

This engine was test fired on the Armadillo Aerospace test stand in January and February, 2011 for a total of 87 seconds in 13 starts with power levels ranging from 21-60\% (limited by the test stand) and ISP values of 150-205 seconds. During these tests, engine acoustics were measured with high speed pressure sensors mounted on the chamber wall and microphones at three locations on the test range. The engine temperature profile was measured with thermocouples in acoustic cavities and welded into the wall at numerous locations along the combustion chamber and nozzle. 


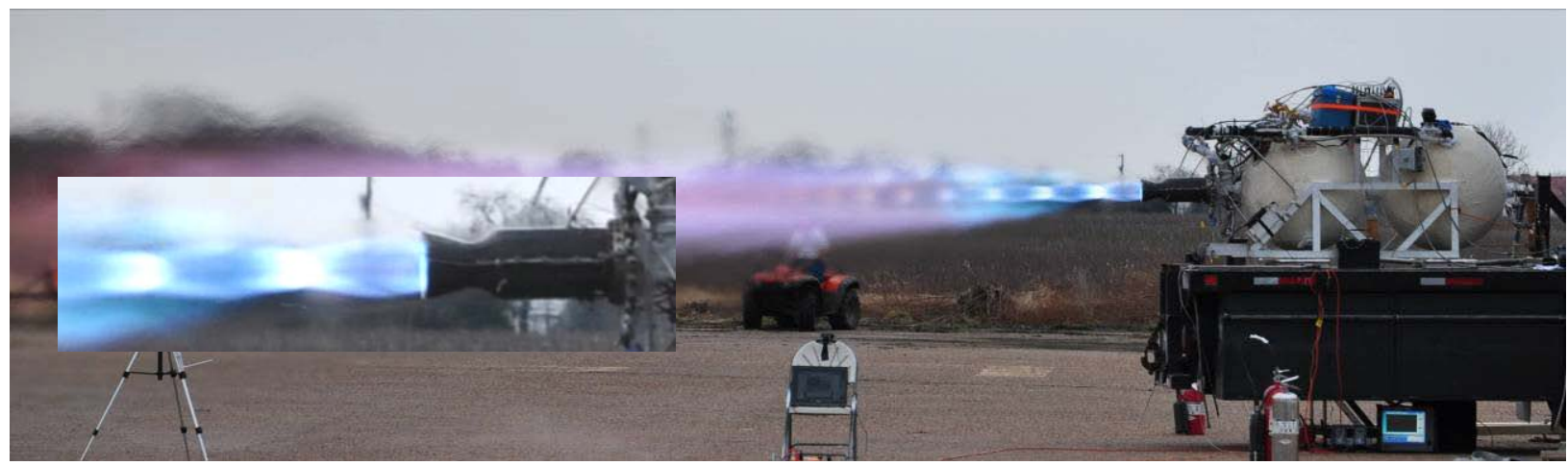

Figure 5: HD3.1 Engine Test Firing at Armadillo Aerospace

It was immediately apparent that the new acoustic cavities were a successful and useful upgrade to the engine. The engine's acoustic cavity ring is comprised of 24 quarter-wave cylindrical acoustic cavities extending radially out from the combustion chamber, immediately downstream of the injector. The surface area of the cavities is equal to $\sim 18 \%$ of the injector face area, allowing sufficient area for several engine harmonic modes to be addressed.

For the first test firing, the acoustic cavity temperature was unknown so the depths of the cavities were set to absorb noise at many different frequencies around the 1T mode that destroyed the HD1 engine, using an assumption of cavity temperature and gas properties. Although the assumption of cavity temperature turned out to be incorrect by $>500$ degrees, the wide spectrum approach still provided protection between 3,000 and 5,500 hz, overlapping the 1T range. Other low frequency noise and a chirp during shutdown were observed during the first test (Figure 6). Between each series of tests, the acoustic cavities were re-tuned by changing the depth of each cavity using $\mathrm{f}=\mathrm{a} /(4 *(\mathrm{~L}+\Delta \mathrm{L}))$. Since the film cooling valve was also being adjusted between each test (discussion later), the local gas temperature in the acoustic cavity was not consistent; making tuning more difficult. Within nine test firings, though, a notable trough was created in the $1 \mathrm{~T}$ range and the lower frequency instabilities were isolated (Figure 6). Note: the $9^{\text {th }}$ test was 8 seconds in duration, so to provide an equivalent noise spectrum comparison; two seconds were removed from the middle of the test, creating an audio file with equivalent data points and startup/shutdown conditions.
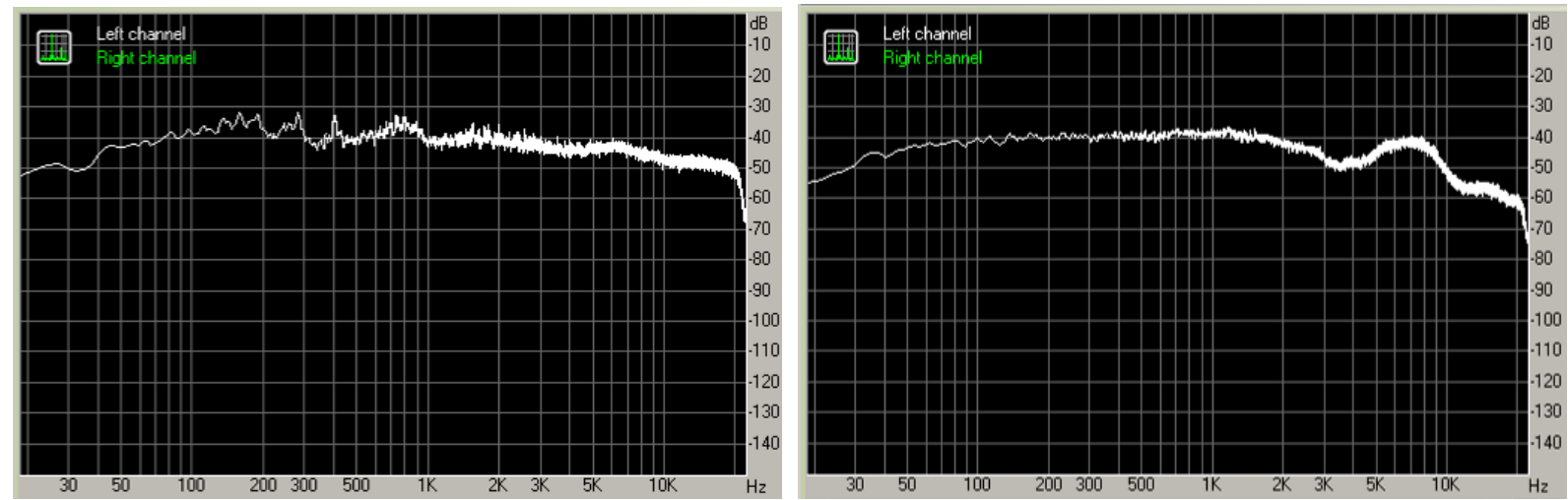

Figure 6: Summary Engine Noise Spectra During the $1^{\text {st }}$ and $9^{\text {th }}$ HD3Test Firings (six second tests)

The engine remains in an overdamped condition around the 1T zone to provide protection for higher thrust engine firings that could not be performed until the engine was installed on the vehicle. When the full thrust test firings are completed, the cavities will be adjusted to minimize the required damping at full thrust and then replaced with fixed depth plugs.

High rate chamber pressure sensors were used to collect $100 \mathrm{kHz}$ combustion acoustic data during the early tests of HD3. The unique wall temperature profile of the film cooled chamber allowed these piezoelectric sensors to be 
mounted directly on the chamber wall. A small section of the chamber near the injector operates in the safe zone for inexpensive uncooled piezoelectric sensors, allowing them to be used in lieu of the standard water-cooled varieties. These sensors observed large and small combustion noise, including signatures not observable on the pad microphones. Strong engine responses, though, could be sensed using microphones and this data ended up being more useful in this application than the high rate chamber pressure data. Since the aim of this project was the rapid development of a reasonable performance engine, the combination of microphones and the acoustic cavities enabled test-to-test variation with very quick turnaround times. After some test firings, a fast Fourier transform of that test's recorded sound was available before the engine had cooled down. This method may not identify all combustion noise and modes but for this application microphones were sufficient.

To investigate the possible effect of depth on acoustic cavity temperature, thermocouples were placed at the rear of two fixed depth cavities: 1" and 2.5" deep. A concern was the proximity of film cooling to the entrance of the cavity and how that could affect cavity tuning. Interestingly, deeper acoustic cavities had up to 500 degree higher gas temperatures at the rear of the cavity than shallower acoustic cavities. To verify that this phenomenon was not caused by the injector pattern, the locations of the two test cavities were changed with similar results. The temperature profile down the length of the shallow vs. deep cavity was not measured but will be during future static test firings.

Another research project on this rapid prototype engine was variable film cooling, with the intent of developing an entrainment coefficient for liquid $\rightarrow$ gas methane film cooling, thereby improving performance on future engines. During the 13 hotfires at AA, film cooling was decreased from the maximum 32\% total methane flow and the effect on chamber wall temperature was measured.

On test firing \#7 a change to the injector orifices, and an updated film cooling flowrate of $19 \%$ resulted in a 6" long "trench" erosion in the chamber wall extending into the subsonic nozzle and through $\sim 80 \%$ of the wall thickness in the deepest location. Test stand time is valuable, though, so to stay on schedule the film cooling was increased and testing continued without further erosion. This was the second of three such erosion incidents - each was weld repaired and the combustion chamber/nozzle assembly is still flying.

During the initial flights of Morpheus, film cooling is set at $32 \%$. As we gain experience with the vehicle the variable film cooling experiment will resume.

The engine film cooling orifices were modified many times to cool injector-related hot spots on the chamber wall. Between engine tests 4-5, $80 \%$ of the film cooling mass flow was migrated from the injector perimeter to a new film cooling ring immediately downstream of the acoustic cavity ring. The remaining film coolant is used to cool the acoustic cavity inlets. Dubbed HD3.1, this engine was better able to cool the chamber wall by passing methane through the acoustic cavity ring and injecting it directly onto the chamber wall, rather than forcing the methane film cooling jets to flow past the acoustic cavities (Figure 7). The HD3.2 upgrade included a few additional tweaks to the film cooling and a new valve stack necessary for installation in the Morpheus vehicle (Figure 8). 


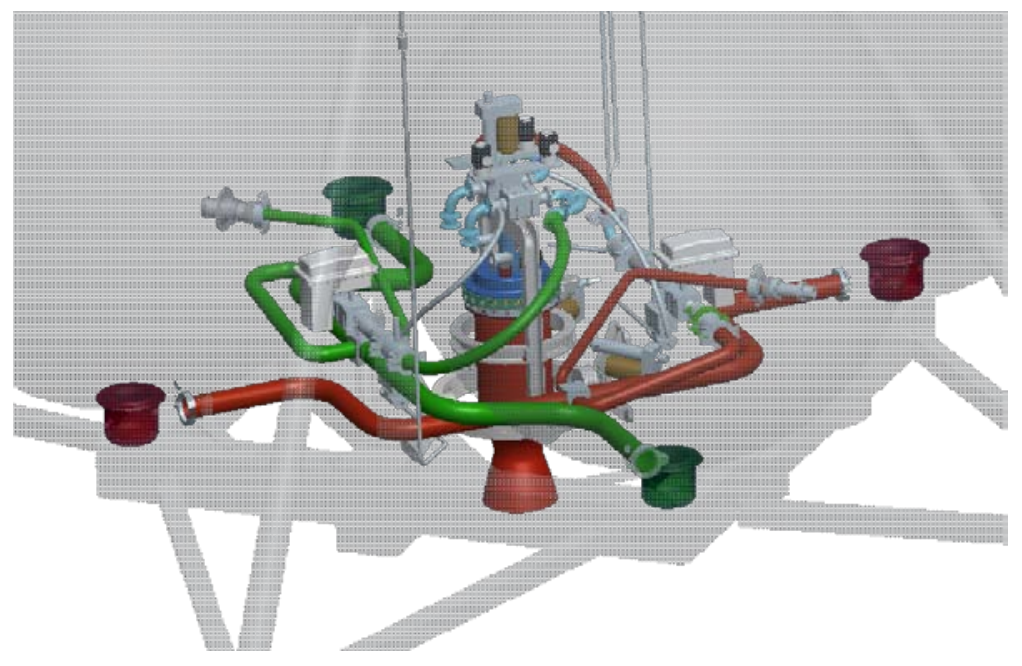

Figure 8: CAD Drawing of Engine and Plumbing In Morpheus
This engine development process was focused on achieving stable, steady-state performance as fast as possible to support looming Morpheus vehicle flights. Unfortunately, along the way we traded long life materials for less expensive/faster production stainless steel and we also gave up the opportunity to research some of the combustion, acoustic, and chamber cooling phenomena for the sake of rapid development. As a result, the HD3.2 engine has a short lifespan but is a stable platform for early Morpheus flights. Its immediate successor (HD4) is likely to be a successful upgrade but for notable departures from the HD3.2 baseline some lessons will likely have to be learned again.

\section{Morpheus Flight Testing}

Morpheus flight testing began with a series of hotfire tests on April 14, 2011 (4 tests, 104 seconds total). This test series was performed with the vehicle suspended from a crane and also anchored to the ground via insulated straps. This test was the first time the Morpheus software was used to operate the engine, and four attempts were required to ignite the engine the first time. Fortunately the software could be modified quickly between each test firing. Five days later, after resolving a few bugs in the system another 4 suspended hotfire tests were performed (54 seconds).

On April 25, we attempted to fly Morpheus for the first time. The tether flight configuration involves hanging the vehicle under a 100-ton crane, suspended with Morpheus's landing pads five feet off the ground. Heavy string is used to keep the vehicle from rotating under windy conditions. Additionally, an energy absorber is placed between the vehicle and the crane hook, reducing jerk loads into the crane. During this first flight attempt, the engine lit as expected but an overly sensitive abort trigger terminated the flight immediately after the transition from the ignition sequence to mainstage.

Two days later we tried again but this time a valve driver failed during ignition, causing the engine to skip its ignition sequence and light at $100 \%$ throttle. The resulting premature launch prior to vehicle flight control handover to GN\&C caused a chaotic flight path restrained by the tether and crane. This flight was terminated using the backup flight termination system - a motor driven ball valve upstream of each propellant flexline, activated by an independent radio system.

Following six days of inspections and code/data reviews, two tether flights were performed with successful ignitions and transitions to active GNC control. During both flights, however, the vehicle was wobbly and each flight was terminated early by the onboard GNC system.

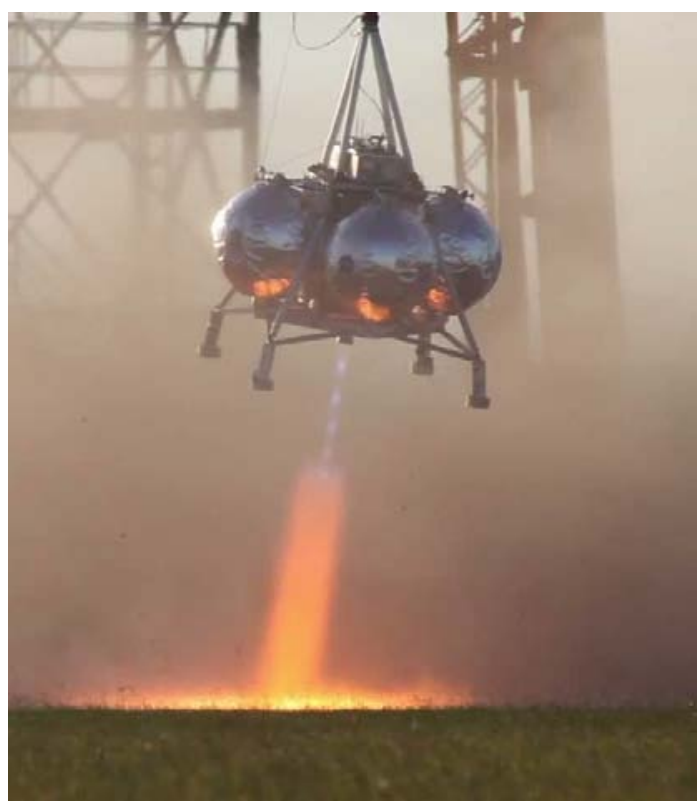

Figure 9: Morpheus Hovering During Tether Test 3 
- First Complete Flight -

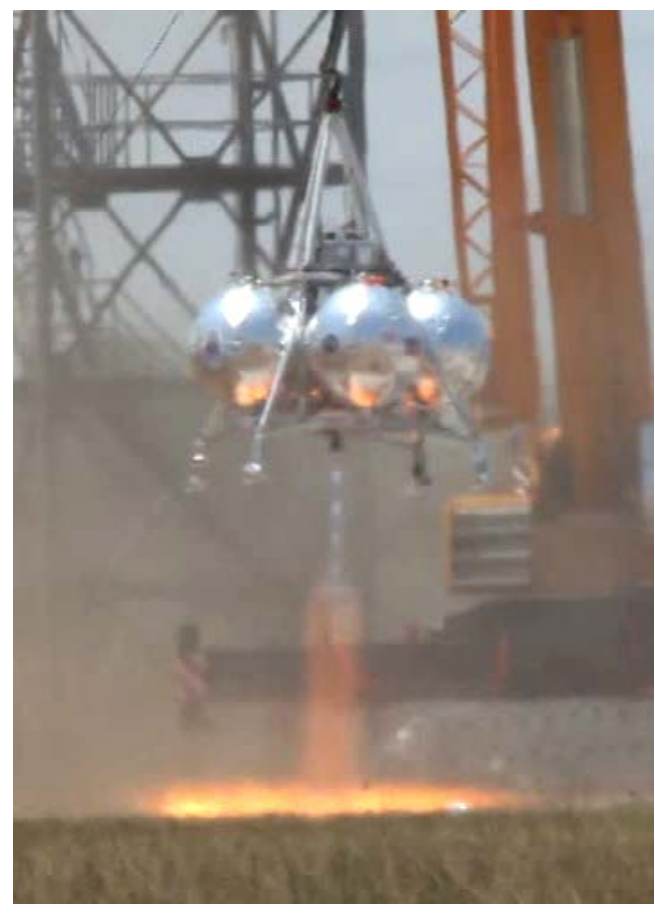

Figure 10: Morpheus Hovering During Tether Test 5
On June 1, 2011, still under tether protection, the Morpheus vehicle few its first complete flight: including a nominal ignition, steady ascent to 10 feet, engine throttling for altitude hold for 30 seconds, descent, and "landing" on the tether. Total flight time: 40 seconds.

The average liftoff weight of Morpheus during the first five tether flights was $\sim 2,500 \mathrm{lbs}$ and the target takeoff acceleration is between 1.1 and $1.2 \mathrm{~g}$ 's. Typical takeoff thrust produced by the engine is $\sim 3,000 \mathrm{lbs}$, or $72 \%$ power level. Hence, this engine has not been provided with a condition to test its upper power level ranges but will be in the near future as longer duration/heavier flights are attempted. The installed HD3.2 engine has a similar acoustic signature to Figure 6, although with more damping in the $2 \mathrm{~T}$ range. This provides some confidence that the engine will tolerate increased power levels before exciting tangential instabilities.

The HD3.2 engine will continue to be used during the upcoming Morpheus tether flights and subsequent free flights, but will likely be replaced with the new HD4 engine before the planned high altitude flights. HD4 is essentially a repackaging of the HD3.2 engine with minor enhancements to the injector pattern and film cooling. HD4 is currently being manufactured at JSC.

To date, the HD3.x engine has 26 starts with 354 seconds of total run time. Over the course of testing at JSC, the engine and vehicle have demonstrated stable operation between $12-72 \%$ power level, including the rapidly changing throttle levels associated with hover flight and two long duration runs at very low power levels without exciting chug instability.

This success-driven development process produced an engine quickly and inexpensively, making acceptable compromises on performance for the sake of speed and cost. This approach worked well for the Morpheus program and future engines for the Morpheus program will follow similar tenets, although with increasing performance goals. 